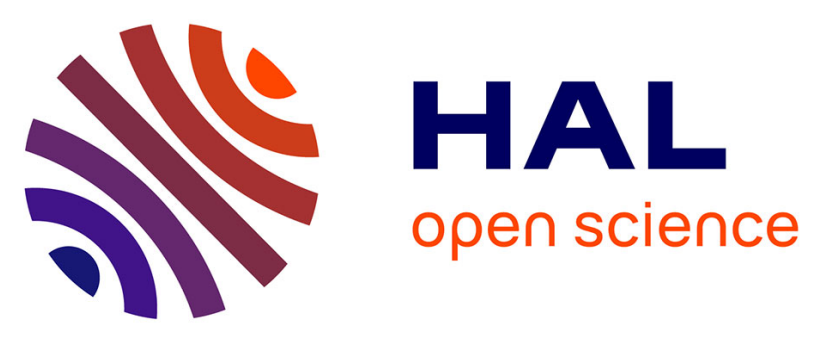

\title{
Monitoring Human Neutrophil Activation by a Proteinase 3 Near-Infrared Fluorescence Substrate-Based Probe
}

Ahlame Saidi, Mylène Wartenberg, J.B Madinier, Guy Ilango, Seda Seren, Brice Korkmaz, Fabien Lecaille, Vincent Aucagne, Gilles Lalmanach

\section{To cite this version:}

Ahlame Saidi, Mylène Wartenberg, J.B Madinier, Guy Ilango, Seda Seren, et al.. Monitoring Human Neutrophil Activation by a Proteinase 3 Near-Infrared Fluorescence Substrate-Based Probe. Bioconjugate Chemistry, 2021, 32 (8), pp.1782-1790. 10.1021/acs.bioconjchem.1c00267 . hal-03525228

\section{HAL Id: hal-03525228 \\ https://hal.science/hal-03525228}

Submitted on 13 Jan 2022

HAL is a multi-disciplinary open access archive for the deposit and dissemination of scientific research documents, whether they are published or not. The documents may come from teaching and research institutions in France or abroad, or from public or private research centers.
L'archive ouverte pluridisciplinaire HAL, est destinée au dépôt et à la diffusion de documents scientifiques de niveau recherche, publiés ou non, émanant des établissements d'enseignement et de recherche français ou étrangers, des laboratoires publics ou privés. 
This document is confidential and is proprietary to the American Chemical Society and its authors. Do not copy or disclose without written permission. If you have received this item in error, notify the sender and delete all copies.

\section{Monitoring of human neutrophil activation by a proteinase 3 near-infrared fluorescence substrate-based probe}

\begin{tabular}{|r|l|}
\hline Journal: & Bioconjugate Chemistry \\
\hline Manuscript ID & bc-2021-00267v.R1 \\
\hline Manuscript Type: & Article \\
\hline Author: & n/a \\
\hline Complete List of Authors: & $\begin{array}{l}\text { Saidi, Ahlame; Université de Tours, INSERM UMR1100 - Centre d'études } \\
\text { des pathologies respiratoires (CEPR) } \\
\text { Wartenberg, Mylène; Université de Tours, INSERM UMR1100 - Centre } \\
\text { d'études des pathologies respiratoires (CEPR) } \\
\text { Madinier, Jean-Baptiste; CBM, Centre de Biophysique Moléculaire } \\
\text { Ilango, Guy; Université de Tours } \\
\text { Seren, Seda; Université de Tours } \\
\text { Korkmaz, Brice; Université de Tours, INSERM UMR1100 - Centre } \\
\text { d'études des pathologies respiratoires (CEPR) } \\
\text { Lecaille, Fabien; Université de Tours, INSERM UMR1100 - Centre } \\
\text { d'études des pathologies respiratoires (CEPR) } \\
\text { AUCAGNE, Vincent; CBM, Centre de Biophysique Moléculaire } \\
\text { Lalmanach, Gilles; Université de Tours, INSERM UMR1100 - Centre } \\
\text { d'études des pathologies respiratoires (CEPR) }\end{array}$ \\
\hline
\end{tabular}

\section{SCHOLARONE Manuscripts}




\section{Table of Contents graphic (TOC)}

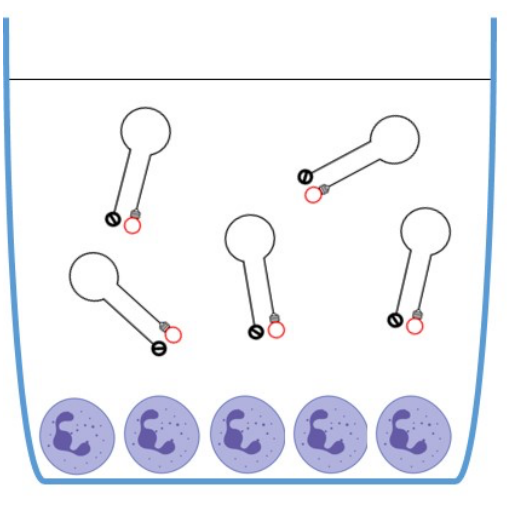

Quiescent neutrophils

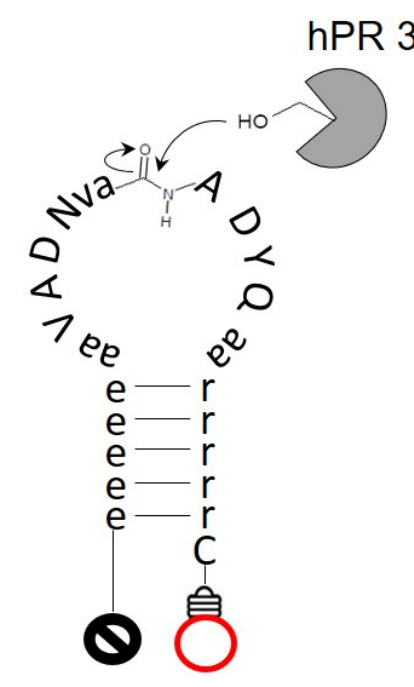

Pro3-SBP

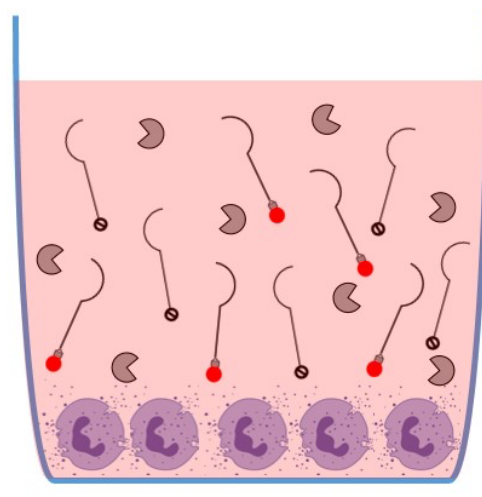

Activated neutrophils 


\title{
Monitoring of human neutrophil activation by a proteinase 3 near-infrared fluorescence substrate-based probe
}

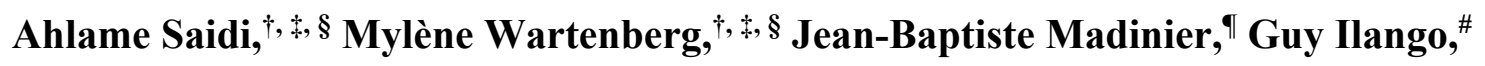 \\ Seda Seren, ${ }^{\dagger},+f$ Brice Korkmaz, ${ }^{\dagger}, *$ Fabien Lecaille, ${ }^{\dagger, *}$ Vincent Aucagne, ${ }^{\natural}$ and \\ Gilles Lalmanach ${ }^{\dagger, \ddagger}, *$
}

\author{
†Université de Tours, Tours, 37032, France \\ *INSERM, UMR 1100, Research Center for Respiratory Diseases (CEPR), Team: "Proteolytic \\ Mechanisms in Inflammation", Tours, 37032, France \\ " CNRS UPR 4301, Center for Molecular Biophysics (CBM), Team: "Molecular, Structural and \\ Chemical Biology", Orléans, 45071, France \\ \# IBiSA Electron Microscopy Platform, Université de Tours, Tours, 37032, France \\ $\S$ AS \& MW: Equal contribution to the work \\ ${ }^{f}$ Current address: Centre de Résonance Magnétique des Systèmes Biologiques, UMR 5536 \\ CNRS, Université de Bordeaux, Bordeaux, France. \\ * Corresponding author: Prof. Gilles Lalmanach, INSERM UMR1100, Centre d'Etude des \\ Pathologies Respiratoires (CEPR), Equipe « Mécanismes protéolytiques dans l'inflammation », \\ Université de Tours, Faculté de Médecine, 10 Boulevard Tonnellé, 37032 Tours cedex, France. \\ Tel: (+33) 2473661 51. Mail: gilles.lalmanach@univ-tours.fr
}




\begin{abstract}
A near-infrared fluorescent (NIRF) substrate-based probe (SBP) was conceived to monitor secreted human proteinase 3 (hPR3) activity. This probe, called pro3-SBP, is shaped by a fused peptide hairpin loop-structure, which associates a hPR3 recognition domain (ValAla-Asp-Nva-Ala-Asp-Tyr-Gln, with Nva: norvaline) and an electrostatic zipper (consisting of complementary polyanionic (D-Glu) $)_{5}$ and polycationic (D-Arg) 5 sequences) driving a tight vicinity of the N- and C- terminal FRET couple (fluorescent donor: sulfoCy5.5; dark quencher: QSY21). Beside its subsequent stability, no intermolecular fluorescence quenching was detected following its complete hydrolysis by hPR3, advocating that pro3-SBP could further afford unbiased imaging. Pro3-SBP was specifically hydrolyzed by hPR3 $\left(\mathrm{k}_{\mathrm{cat}} / \mathrm{K}_{\mathrm{m}}=440,000 \pm\right.$ 5,500 $\mathrm{M}^{-1} \cdot \mathrm{s}^{-1}$ ) and displayed a sensitive detection threshold for hPR3 (sub-nanomolar concentration range), while neutrophil elastase showed a weaker potency. Conversely, pro3SBP was not cleaved by cathepsin G. Pro3-SBP was successfully hydrolyzed by conditioned media of activated human neutrophils, but not by quiescent neutrophils. Moreover, unlike unstimulated neutrophils, a strong NIRF signal was specifically detected by confocal microscopy following neutrophil ionomycin-induced degranulation. Fluorescence release was abolished in the presence of a selective hPR3 inhibitor, indicating that pro3-SBP is selectively cleaved by extracellular hPR3. Taken together, present data support that pro3-SBP could be a convenient tool allowing a straightforward monitoring of human neutrophil activation.
\end{abstract}

\title{
Keywords
}

Cathepsin, Elastase, Near-infrared fluorescence (NIRF), Neutrophil serine protease (NSP), Proteinase 3 


\section{Introduction:}

Neutrophil elastase (NE), proteinase 3 (PR3), and cathepsin G (CatG) are three neutrophil serine proteases (NSPs) that are stored in the primary (azurophil) granules of polymorphonuclear neutrophils (PMNs). ${ }^{1,2}$ NSP4, a less abundant NSP which is also uncovered in the azurophilic granules, was recently identified. ${ }^{3,4}$ Maturation of NSPs occurs through cleavage of a N-terminal dipeptide by cysteine cathepsin C. ${ }^{5}$ NSPs are implicated in a variety of diseases, including ischemic-reperfusion injury, glomerulonephritis, arthritis, bullous pemphigoid, non-alcoholic fatty liver disease or lung diseases (COPD, ARDS, cystic fibrosis). ${ }^{6}$ NSPs have bactericidal and antifungal properties, and were first recognized as digestive enzymes that degrade ingested host pathogens. ${ }^{7}$ A web-like structure of DNA secreted by activated neutrophils (neutrophil extracellular trap, NET) was described as an additional antimicrobial mechanism. ${ }^{8}$ Following recruitment of PMNs, NSPs participate in the alteration of extracellular matrix components at inflammatory sites, and are key regulators of the local inflammatory response, being involved in the control of cellular signaling through the processing of chemokines and the modulation of the cytokine network. ${ }^{2}$

PR3 may be detected both in secondary granules and on membrane-bound secretory vesicles. ${ }^{9}$ Mature PR3 is dormant in the acidic environment of the azurophilic granules and is activated upon translocation to a neutral $\mathrm{pH}$ environment by a slow conformational change. PR3 is primarily regulated by $\alpha 1$-protease inhibitor, serpin B1, and elafin, but not by secretory leukocyte protease inhibitor. ${ }^{10}$ Under pathological conditions, downregulation and/or inactivation of PR3 inhibitors result in an uncontrolled PR3 activity, which may further contribute to tissue damage and inflammatory cascades. More specifically, PR3 participates in the activation of IL-8, TNF- $\alpha$ and IL-1 $\beta$ as well the degradation of fibronectin or laminin, and is involved in the maturation of cathelicidin hCAP-18 to generate LL-37, a potent antimicrobial peptide. ${ }^{11}$ Also, PR3 favors endothelial cell apoptosis and takes part in platelet activation and regulation of granulopoiesis. ${ }^{12-14}$ Furthermore, PR3 is the main target antigen of anti-neutrophil cytoplasmic autoantibodies (ANCA) in granulomatosis with polyangiitis (GPA). ${ }^{15}$ Structural and functional properties of human PR3 (hPR3) were initially described as similar to those of human NE (hNE). hPR3 and hNE share an analogous catalytic mechanism ${ }^{16}$ and the elucidation of the crystal structure of hPR3 has confirmed that both enzymes display a common fold. ${ }^{17,18}$ Despite hPR3 and hNE preferentially accommodate small hydrophobic residues in the S1 pocket, their different substrate specificities have been exploited to develop synthetic inhibitors and FRET peptidyl substrates of human PR3. ${ }^{19-22}$ 
Although hPR3 is considered as a relevant therapeutic target, its precise contribution to some diseases remains still debated. Accordingly, the appraisal of hPR3 activity within living cells and extracellular milieu, using newly developed chemical biology tools, will obviously assist to clarify the role of hPR3 during pathophysiological events. Foremost strategies of probe design to profile enzymatic activity of serine and cysteine proteases, from cell to in vivo assays, were recapitulated elsewhere. ${ }^{23-25}$ Activity-based probes (ABPs) consist of an electrophilic warhead that binds stoichiometrically and covalently to the catalytic nucleophilic residue of the active site, coupled to a linker or a targeting sequence, and a reporter group for visualization, thus allowing to accurately pinpoint the protease activity. During the last decade, potent chemical probes have been developed for assessment of NSP activities, including hPR3 activity. ${ }^{26-34}$ However, ABPs do not permit signal amplification, which can result in lowintensity signals. By contrast, substrate-based probes (SBPs) contain a peptidyl (or pseudopeptidyl) backbone linked to a tag (usually a fluorophore) and a quencher group, allowing a stronger reporter signal amplification. A detrimental counterpart is that, after cleavage, released low molecular weight reporters could diffuse faster than an ABP-protease covalent complex and thus lead to unfocused signals or images. ${ }^{35,36}$

A recent article reported a straightforward method for monitoring $\mathrm{hNE}$ and CatG activity of purified neutrophils, but not hPR3 activity. ${ }^{37}$ Alternatively, methods for monitoring hPR3 are currently based on measurements of its enzymatic activity by peptidyl substrates. ${ }^{38}$ Given that the extracellular activity of PR3 is basically associated to stimulation of PMNs and release of NSPs stored in primary granules, an attractive manner to survey activation of neutrophils is to design and synthetize a near-infrared fluorescence SBP. Hence, we conceive a cell-impermeable near-infrared fluorescence (NIRF) SBP for monitoring active, secreted hPR 3. ${ }^{39}$ We therefore designed a peptide hairpin loop-like structure that consists of a hPR3 recognition sequence and an electrostatic zipper, driving a close vicinity of the $\mathrm{N}$ - and $\mathrm{C}$ terminal FRET couple (fluorescent donor: sulfoCy5.5; non-fluorescent dark quencher: QSY21). The recognition sequence is derived from both a hPR3 substrate (Abz-Val-Ala-Asp-Nva-AlaAsp-Tyr-Gln-EDDnp, with Nva: norvaline) and azapro-3, its corresponding azapeptide inhibitor (Abz-Val-Ala-Asp-azaNva-Ala-Asp-Tyr-Gln-3-nitro-Tyr). ${ }^{40}$ First, the probe, called pro3-SBP, was characterized in vitro. Then, the ability of pro3-SBP to monitor secreted hPR3 and thus neutrophil activation was endorsed. Despite a scattered fluorescence signal, a pivotal advantage of pro-SBP3, which emits in the near infrared, is to provide a sensitive detection level of hPR3, allowing a laid-back and fast visualization of neutrophil activation. 


\section{Results \& discussion}

\section{Design and characterization of the proteinase 3 NIRF probe}

The hPR3 recognition domain was derived from both a peptidyl substrate and an azaNva-containing peptide inhibitor initially designed for targeting neutrophil hPR3 ${ }^{40}$ (see schematic representation: Figure 1a). The electrostatic zipper corresponded to a short double strand consisting of a complementary pair of a polyanionic (D-Glu) 5 segment and a (D-Arg) 5 , a 5-mer polycation. The zipper was covalently linked to the $\mathrm{N}$ - and $\mathrm{C}$-termini of $\mathrm{hPR} 3$ recognition peptide via (D-Ala) 2 spacers. The fluorescence donor-acceptor pair consisted of $i /$ a dark quencher (QSY21) conjugated to the peptide through an amide bond with the N-terminal amino group of D-Glu and ii/ a maleimido-functionalized fluorescent dye (sulfoCy5.5) which was linked to a C-terminal Cys via a thioether bond. The presence of the double strand polycationic/polyanionic zipper drives a tight vicinity between the fluorescent donor group and QSY21, the non-fluorescent acceptor quencher, leading to an efficient intramolecular FRET in the absence of proteolytic cleavage. Consequently, QSY21 returns from the excited state to the ground state via non-radiative decay pathways, without the emission of light. ${ }^{41}$ While cationic Arg-rich peptides as well poly-Arg 8 to 15 -mers translocate through membranes and may act as potent $\mathrm{CPPs}^{42,43}$, peptides containing less than six L/D -Arg residues are ineffective CPPs. ${ }^{44}$ Accordingly, presence of a double strand electrostatic zipper consisting of only five D-Glu/DArg pairings ensure the inability of NIRF probe to cross membranes, avoiding any targeting of intracellular hPR $3 .{ }^{45}$ A similar strategy was successfully used to design a selective NIRF probe of secreted CatS. ${ }^{46}$ 
a)

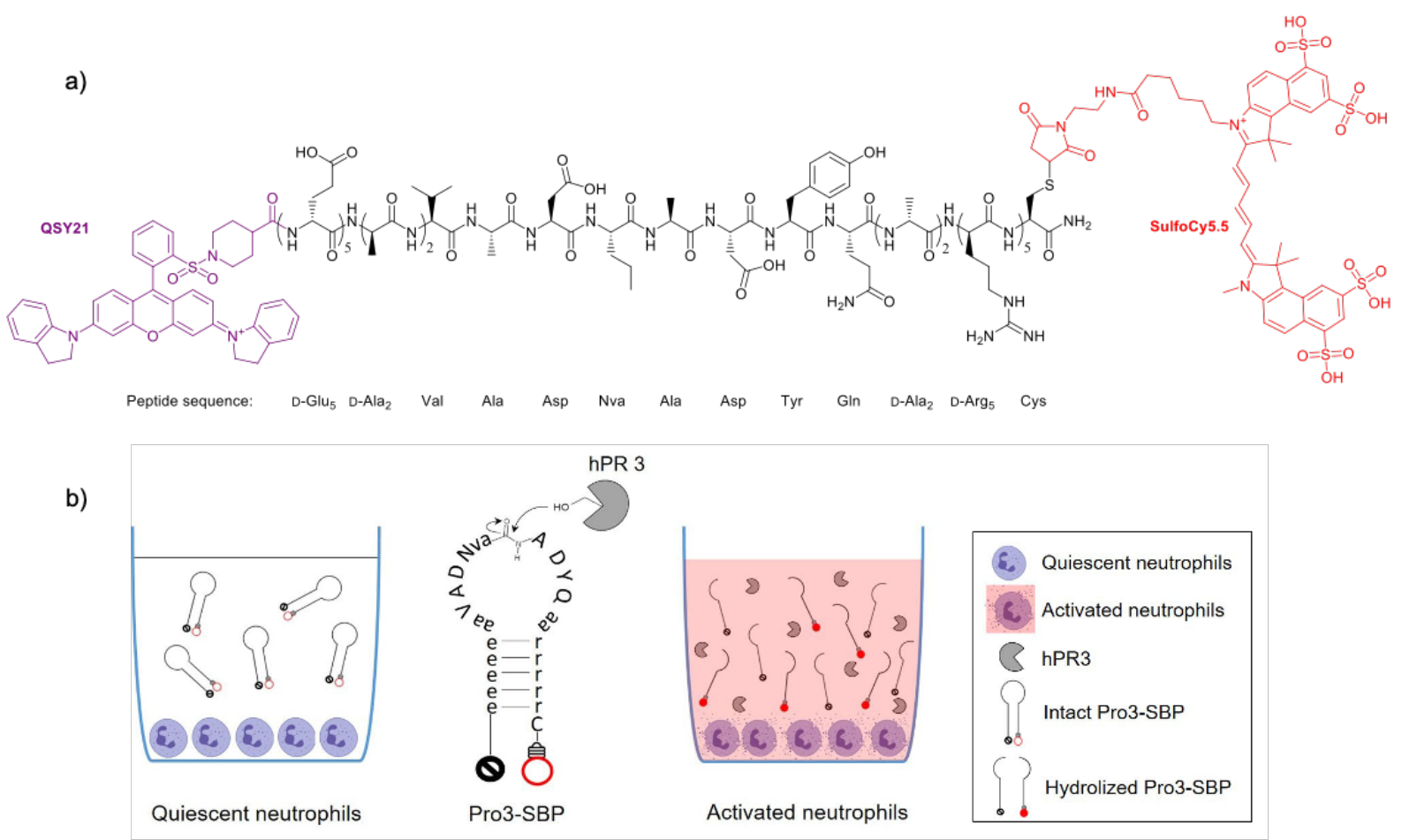

Figure 1: structure and design of the hPR3 substrate-based probe.

(a) Structure of the NIRF probe (pro3-SBP). The PR3 recognition domain (VADXADYQ, with $\mathrm{X}=$ norvaline, Nva) was derived from a selective azaNva-containing peptide inhibitor of human neutrophil PR3, hPR3. The electrostatic zipper corresponds to a complementary (D-Glu $)_{5} /(\mathrm{D}-\mathrm{Arg})_{5}$ pair. The PR3 recognition peptide is flanked in both N- and C-positions by a (D-Ala) 2 spacer. The FRET donor-acceptor pair consists of a dark quencher (QSY21) and a maleimido-functionalized fluorophore (sulfoCy5.5) which is linked to a C-terminal Cys. (b) Cartoon representation. General scheme for monitoring neutrophil activation by pro3-SBP.

Pro3-SBP was synthesized as detailed extensively in the experimental part. The characteristics of the purified probe (RP-HPLC profile, ESI-MS spectrum and UV-vis spectrum) were disclosed in the supplementary file: Figure S1. Stability of the intramolecularly quenched fluorescent pro3-SBP was further examined. No fluorescence signal corresponding to a selfdequenching $\left(\lambda_{\mathrm{ex}}=684 \mathrm{~nm} ; \lambda_{\mathrm{em}}=710 \mathrm{~nm}\right.$ ) was observed after one hour of incubation, supporting that the intramolecular FRET between sulfoCy5.5 and QSY21 was robust. This was confirmed by preincubation of pro3-SBP in the presence of a high ionic strength $(1 \mathrm{M} \mathrm{NaCl})$ where no dequenching was observed. Alternatively, addition of hPR3 led to a straight fluorescence release, indicating that the cleavage within the recognition sequence triggered an immediate dissociation of the salt bridges between (D-Glu) 5 and (D-Arg) $)_{5}$ strands, directing the dequenching of the sulfoCy5.5 donor/QSY21 acceptor pair, as previously described for a molecular SBP conjugate of similar assembly, but carrying a different donor/acceptor pair. ${ }^{46}$ Moreover, cleavage of increasing amounts of pro3-SBP $(0-8 \mu \mathrm{M})$ conducted a linear dose- 
dependent level of emitted fluorescence $\left(\mathrm{R}^{2}=0.98\right)$, demonstrating that intermolecular fluorescence quenching did not occur.

\section{Specificity of the hPR3 substrate-based probe}

As indicated before, incubation of pro3-SBP with hPR3 conducted to a NIRF release. As expected, the cleavage site was located at the Nva-Ala bond (MALDI mass spectrometry analysis) (Figure S2). The second-order rate constant, which was determined under pseudo-first order conditions, corresponded to $\mathrm{k}_{\mathrm{cat}} / \mathrm{K}_{\mathrm{m}}=440,000 \pm 5,500 \mathrm{M}^{-1} \cdot \mathrm{s}^{-1}$ (with Michaelis constant $\mathrm{K}_{\mathrm{m}}=1.33 \mu \mathrm{M}$ ), supporting a worthy specificity (Table I).

Table I: Kinetic parameters (second-order rate constant) for the hydrolysis of pro3-SBP by human proteases.

\begin{tabular}{lc}
\hline & $\mathrm{k}_{\text {cat }} / \mathrm{K}_{\mathrm{m}}\left(\mathrm{M}^{-1} \cdot \mathrm{s}^{-1}\right)$ \\
Proteases & \\
\cline { 2 - 2 } hPR3 & $440,000 \pm 5,500$ \\
hNE & n.h. \\
CatS & $33,000 \pm 3,000$ \\
CatL & n.h. \\
CatB & $<1,000$ \\
CatH & n.h. \\
CatD & n.h. \\
MMP-8 & n.h. \\
MMP-9 & n.h. \\
MMP-12 & n.h. \\
& n.h. \\
\hline
\end{tabular}

Determination of the second-order rate constants were carried out under pseudo first-order conditions as detailed in the experimental section. Kinetic data were reported as means \pm S.D ( $n=3$, three independent experiments). n.h., no hydrolysis.

Also, a similar specificity constant was maintained, compared to the parent FRET substrate (Abz-Val-Ala-Asp-Nva-Ala-Asp-Tyr-Gln-EDDnp) ${ }^{40}$, sustaining that substitution of the Abz/EDDnp pair by a bulky hydrophobic donor/quencher (sulfoCy5.5/QSY21) pair did not affect the $\mathrm{k}_{\mathrm{cat}} / \mathrm{K}_{\mathrm{m}}$ value, which mostly relied on the peptidyl hPR3 recognition pattern. Pro3SBP was also cleaved, but to a lesser extent, by $\mathrm{hNE}\left(\mathrm{k}_{\mathrm{cat}} / \mathrm{K}_{\mathrm{m}}=33,000 \pm 3,000 \mathrm{M}^{-1} \cdot \mathrm{s}^{-1}\right)$. Analysis of the hydrolysis products by mass spectrometry demonstrated the presence of two cleavage sites for hNE, located at the Nva-Ala bond and its neighboring Ala-Asp bond (respective cleavage ratio: $\sim 55 \%$ vs $\sim 45 \%$ ) (Figure S3). Also, cathepsin L hydrolyzed slightly pro3-SBP (estimated $\mathrm{k}_{\text {cat }} / \mathrm{K}_{\mathrm{m}}<1,000 \mathrm{M}^{-1}$. $\mathrm{s}^{-1}$ ). On the other hand, pro3-SBP was not susceptible to 
hydrolysis by CatG. Similarly, biologically relevant aspartic CatD, cysteine cathepsins B, H and S, MMP-8 and MMP-9, which are matrix metalloproteinases produced by neutrophils, as well as MMP-12 (macrophage elastase) did not hydrolyze pro3-SBP.

We evaluated the sensitivity (i.e. detection limit) of pro3-SBP. In the presence of a constant amount of pro3-SBP $(0.5 \mu \mathrm{M})$, fluorescence release was observed with subnanomolar concentrations of hPR3 (IVIS Caliper Lumina XR imaging system) (Figure 2a). Alternatively, in the presence of a constant concentration of hPR3 $(5 \mathrm{nM})$, we detected a fluorescence threshold with submicromolar concentration $(0.25 \mu \mathrm{M})$ of pro3-SBP (Figure $2 b$ ).

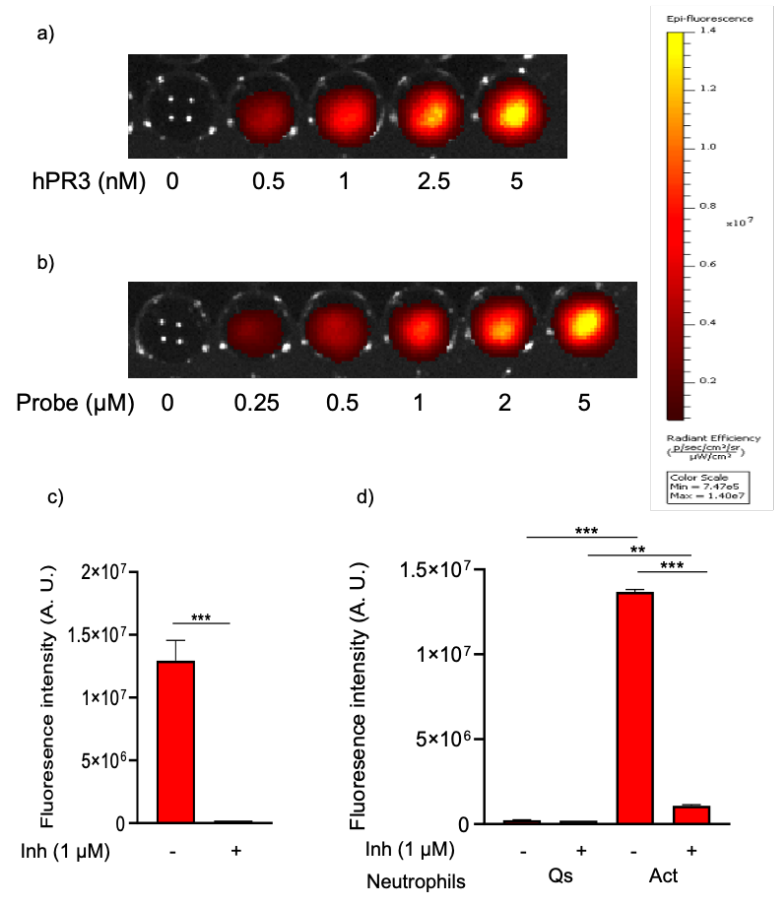

Figure 2: Detection threshold and selectivity of pro3-SBP.

(a) Increasing amounts of hPR3 $(0-5 \mathrm{nM})$ were incubated in the presence of pro3-SBP $(0.5 \mu \mathrm{M})(0.05 \mathrm{M}$ HEPES buffer, $\mathrm{pH} 7.4,0.05 \% \mathrm{NP} 40,150 \mathrm{mM} \mathrm{NaCl})$. After $5 \mathrm{~min}$, fluorescence release was measured $\left(\lambda_{\mathrm{ex}}=640 \mathrm{~nm}\right.$, $\lambda_{\mathrm{em}}=675 \mathrm{~nm} ; 5 \mathrm{~s}$ exposure; IVIS Caliper Lumina XR imaging system). (b) PR3 $(5 \mathrm{nM})$ was incubated in the presence of increasing concentrations of pro3-SBP $(0-5 \mu \mathrm{M})$, before recording the fluorescence release $(\mathrm{t}=25 \mathrm{~min})$. (c) Control experiments were conducted by pre-incubating for $30 \mathrm{~min}$ PR $3(5 \mathrm{nM})$ in the presence of a selective irreversible hPR3 inhibitor (Inh: Biotinyl-Val-Tyr-Asp-Nva-P(O-C $\left.\left.\mathrm{C}_{6} \mathrm{H}_{4}-4-\mathrm{Cl}\right)_{2}, 1 \mu \mathrm{M}\right)$. After addition of pro3-SBP $(5 \mu \mathrm{M})$, fluorescence release was monitored (IVIS Caliper Lumina XR imaging system, $t=10 \mathrm{~min}$ ). Data were expressed as mean \pm SD fluorescence intensity (A.U., arbitrary units). Statistical analyses were performed using Mann-Whitney $U$ test $(\mathrm{n}=3, * * *: P<0.0005)$. (d) Following incubation of neutrophils with ionomycin, as detailed in the experimental section, conditioned media of activated neutrophils (Act) were withdrawn and incubated with pro3-SBP $(5 \mu \mathrm{M})$. Fluorescence release was further examined (IVIS Caliper Lumina XR imaging system, $t=30 \mathrm{~min})$. The same experiments were carried out in the presence of unstimulated neutrophils (quiescent, Qs). Results were expressed as mean \pm SD fluorescence intensity (A.U., arbitrary units). Statistical analyses were performed using Kruskal-Wallis test $(\mathrm{n}=3, * *: P<0.005, * * *: P<0.0005)$. Signal selectivity was checked in the presence of the hPR3 inhibitor (Inh).

The fluorescence release correlated markedly with hPR3 enzymatic activity, since there was a full impairment of signal in the presence of Biotinyl-Val-Tyr-Asp-Nva- $\mathrm{P}\left(\mathrm{O}-\mathrm{C}_{6} \mathrm{H}_{4}-4-\mathrm{Cl}\right)_{2}$ (Figure 2c), a potent peptidyl di(chlorophenyl)-phosphonate ester inhibitor, previously used to 
selectively inhibit extracellular activity of hPR3 in sputa from cystic fibrosis patients. ${ }^{31}$ Following treatment of purified neutrophils by a calcium ionophore, PMN conditioned medium was collected and pro3-SBP was added. An extensive NIRF signal, which was abolished in the presence of Biotinyl-Val-Tyr-Asp-Nva-P(O-C $\left.\mathrm{C}_{6} \mathrm{H}_{4}-4-\mathrm{Cl}\right)_{2}$, was monitored (Figure 2d). Conversely to ionomycin-activated neutrophils, hydrolysis of pro3-SBP was undetectable in supernatants issued from untreated PMNs. Present results indicate that the specific fluorescence release from cleavage of pro3-SBP corresponded to extracellular hPR3 activity, which could be entirely abrogated by addition of the hPR3 inhibitor. ${ }^{31}$ Data also support that pro3-SBP could be a valuable tool for monitoring the secretion of mature active hPR3 by activated neutrophils, since no NIRF signal was detected in the presence of quiescent neutrophils.

\section{Imaging of secreted hPR3 by confocal microscopy}

Both ionomycin-treated and untreated neutrophils were cultured for $4 \mathrm{~h}$. After removal of non-adherent PMNs, pro3-SBP $(10 \mu \mathrm{M})$ was immediately added to the culture medium and imaging was performed by confocal fluorescence microscopy. In a preliminary way, a cell viability assay was performed since incubation of neutrophils with ionomycin results in an increase of intracellular $\mathrm{Ca}^{2+}$ levels and a subsequent decrease of cell viability. ${ }^{47,48}$ Accordingly, we observed a decrease of cell viability following addition of ionomycin compared to untreated neutrophils. However, the addition of pro3-SBP did not induce any significant modification of the viability of ionomycin-activated neutrophils as well quiescent cells (Figure S4), which supports that pro3-SBP did not exhibit deleterious cellular outcomes under the present experimental conditions. Confocal microscopy analysis showed that NIR fluorescence release was rapidly detected for activated neutrophils, but not for quiescent cells (Figure 3a-b). The emitted fluorescence was found exclusively in the extracellular medium, but not intracellularly within living neutrophils, as supported by bright-field microscopy, thus validating our probe design strategy. In parallel, control trials, cell media of both quiescent, and activated PMNs were withdrawn and hPR3 activity was measured by transmitted light microscopy. Addition of an irreversible phosphonate hPR3 inhibitor ${ }^{26}$ fully abrogated the fluorescence release (Figure 3c), confirming that pro3-SBP is a potent and selective SBP for hPR3 imaging following neutrophil activation.

Present data confirmed that the peptide hairpin loop-structure of pro3-SBP is highly stable in culture media. Indeed, no fluorescence signal, associated to a spontaneous selfdequenching, was detected for quiescent neutrophils in the absence of hPR3 release, supporting the selective character of pro3-SBP. Moreover, data endorsed that pro3-SBP is a potent probe, 
aiming to image secreted/extracellular hPR3 activity following activation of quiescent neutrophiles and degranulation by calcium ionophore. Nevertheless, a limitation for the use of pro3-SBP is that the released reporter group bearing Cy5.5 led to an unfocused signal, which is due to its diffusion into the extracellular medium, consistently with its substrate-derived backbone. ${ }^{35}$ Nevertheless, a fine NIRF signal-noise ratio should be noticed, as demonstrated by the lack of fluorescence background of uncleaved pro3-SBP. Also, the worthy turnover rate constant value of pro3-SBP $\left(\mathrm{k}_{\mathrm{cat}} / \mathrm{K}_{\mathrm{m}}=440,000 \pm 5,500 \mathrm{M}^{-1} . \mathrm{s}^{-1}\right)$ thereby makes possible to detect in situ nanomolar concentrations of extracellular active hPR3.
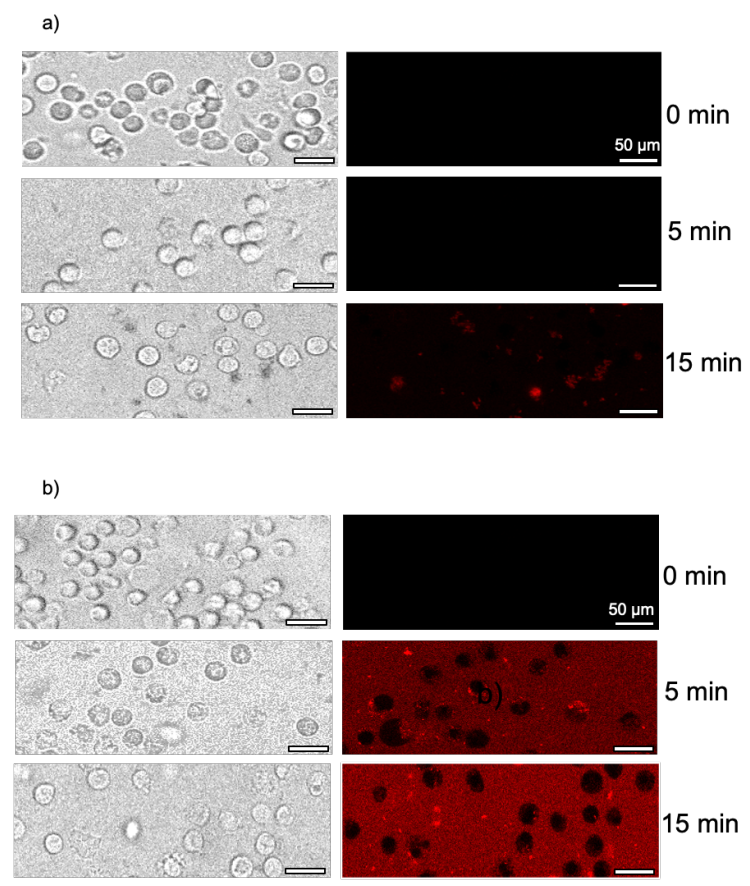

c)

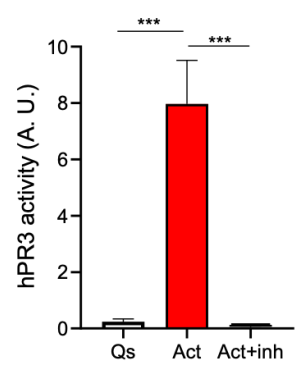

Figure 3: Probing neutrophil activation by confocal microscopy.

(a) Ionomycin-treated neutrophils were seeded in Well Black ibiTreat microplates (Ibidi) as described in "material \& methods" (500,000 neutrophils/well). After removal of non-adherent cells, pro3-SBP $(10 \mu \mathrm{M})$ was immediately added to the culture medium. Imaging was performed by monitoring the NIRF signal release (confocal fluorescence microscopy, Leica SP8 confocal microscope, laser $675 \mathrm{~nm}$, red) at 0,5 , and $15 \mathrm{~min}$ (right panel), using white light as control (left panel). All snapshots were obtained by using objective: $60 \times$ and scale bar: $50 \mu \mathrm{m}$. (b) The selectivity of the NIRF signal was confirmed by carrying out the same experiments in the presence of quiescent neutrophils. (c) hPR3 activity in cell-free supernatants of quiescent (Qs) and activated (Act) neutrophils. Alternatively, media (corresponding to 500,000 neutrophils/well) were withdrawn, and hPR3 activity was measured using ABZ-Val-Ala-Asp-Nva-Ala-Asp-Tyr-Gln-EDDnp $(20 \mu \mathrm{M})$ as substrate $\left(\lambda_{\text {ex }}=320 \mathrm{~nm}, \lambda_{\text {em }}=420\right.$ $\mathrm{nm})$. Biotinyl-Val-Tyr-Asp-Nva-P(O-C $\left.\mathrm{C}_{6} \mathrm{H}_{4}-4-\mathrm{Cl}\right)_{2}(1 \mu \mathrm{M})$, a selective hPR3 inhibitor was used as control 
(Act $+\mathrm{inh})$. Data were expressed as arbitrary units (A.U). Results were analyzed using Kruskal-Wallis test $(\mathrm{n}=3, P$ value $* * *: P<0.0005)$.

In conclusion, current results support that pro3-SBP is a specific NIRF substrate-based probe for monitoring activity of secreted hPR3. In addition to selective and powerful activitybased probes designed by several colleagues to specifically target and visualize hPR3 activity, pro3-SBP may represent an alternative and convenient molecular tool for a casual monitoring of neutrophil activation.

\section{Experimental procedures}

\section{Peptide chemistry:}

General information: All reagents and solvents were used without further purification. Protected amino acids were purchased from Gyros Protein Technology (Uppsala, Sweden). DIEA (di-isopropyl-ethylamine), HPLC gradient-grade MeCN and TFA were purchased from Carlo Erba (Val-de-Reuil, France). Rink amide ChemMatrix resin was purchased from Biotage (Uppsala, Sweden). Sulfo-cyanine5.5 NHS ester was obtained from Lumiprobe GmbH (Hannover, Germany). QSY21 maleimide was purchased from AAT Bioquest (Sunnyvale, CA, USA). Peptide synthesis-grade DMF was purchased from VWR (Fontenay-sous-Bois, France). Ultrapure water was obtained using a Milli-Q water system from Millipore (Molsheim, France). Polypropylene syringes fitted with polypropylene frits were purchased from Torviq (Niles, MI, USA) and were equipped with PTFE (5 polytetrafluoroethylene) stopcock from Biotage.

Peptide characterization and purification: HPLC analyses were carried out on a Chromaster system equipped with a 5160 pump, a 5430 diode array detector and a 5260 auto sampler. Semi-preparative purifications were carried out on a LaChromElite system equipped with a Hitachi L-2130 pump, a Hitachi L-2455 diode array detector and a Hitachi L-2200 auto sampler. Chromolith High Resolution RP-18e $(150 \AA$, $10 \times 4.6 \mathrm{~mm}, 3 \mathrm{~mL} / \mathrm{min}$ flow rate) columns were used for analysis, and Nucleosil C18 $(300 \AA, 5 \mu \mathrm{m}, 250 \times 10 \mathrm{~mm}, 3 \mathrm{~mL} / \mathrm{min}$ flow rate) for purification. As mobile phases, mixtures of $0.1 \%$ TFA in $\mathrm{H}_{2} \mathrm{O}$ (A) and $0.1 \%$ TFA in $\mathrm{MeCN}$ (B) were used. ESI-MS analyses were carried out on an Agilent 1260 Infinity HPLC system, coupled with an Agilent 6120 mass spectrometer (ESI + mode), and fitted with an Aeris Widepore XB-C18 $2\left(3.6 \mu \mathrm{m}, 150 \times 2.1 \mathrm{~mm}, 0.5 \mathrm{~mL} / \mathrm{min}\right.$ flow rate, $\left.60{ }^{\circ} \mathrm{C}\right)$ column. The reported $\mathrm{m} / \mathrm{z}$ values correspond to the average mass. As mobile phases, mixtures of $0.1 \%$ formic acid in $\mathrm{H}_{2} \mathrm{O}\left(\mathrm{A}^{\prime}\right)$ and $0.1 \%$ formic acid in $\mathrm{MeCN}$ (B') were used. Gradient: 3\% B' for 1 min, 
then 3 to $50 \%$ B' over 15 min. MS spectrum of purified Pro3-SBP was obtained by LC-MS (liquid chromatography coupled to mass spectrometry) analysis using this system.

Solid-phase peptide synthesis: Automated Fmoc-based solid phase peptide syntheses (SPPS) was carried out on a Prelude synthesizer from Protein technologies. Standard side-chain protecting groups were used: $\operatorname{Arg}(\mathrm{Pbf}), \operatorname{Asp}(\mathrm{OtBu}), \mathrm{Cys}(\mathrm{Trt}), \mathrm{Gln}(\mathrm{Trt})$ and $\operatorname{Tyr}(\mathrm{tBu})$. Synthesis was performed on a $25 \mu$ mol-per-reactor scale. Protected L-amino acids ( $250 \mu \mathrm{mol}, 10$ equiv.) were coupled without pre-activation using HCTU (2-(6-chloro-1H-benzotriazole-1-yl)-1,1,3,3tetramethylaminium hexafluorophosphate, $90 \mathrm{mg}, 238 \mu \mathrm{mol}, 9.5$ equiv.) and DIEA ( $87 \mu \mathrm{L}, 500$ $\mu \mathrm{mol}, 20$ equiv.) in NMP ( $3 \mathrm{~mL}$ ) for $30 \mathrm{~min}$. A modified protocol was used for D-amino acids building blocks: protected D-amino acids ( $87.5 \mu \mathrm{mol}, 3.5$ equiv.) were coupled using HATU (1-[bis(dimethylamino)methylene]-1H-1,2,3-triazolo[4,5-b]pyridinium

3-oxide hexafluorophosphate, $32 \mathrm{mg}, 85 \mu \mathrm{mol}, 3.4$ equiv.) and DIEA (30 $\mu \mathrm{L}, 175 \mu \mathrm{mol}, 7$ equiv.) in NMP ( $3 \mathrm{~mL}$ ) for $2 \mathrm{~h}$. After each coupling, capping of potential unreacted amine groups was achieved by treatment with acetic anhydride (143 $\mu \mathrm{L}, 1.51 \mathrm{mmol}, 60$ equiv.), DIEA (68 $\mu \mathrm{L}$, $0.39 \mathrm{mmol}, 15.5$ equiv.) and $\mathrm{HOBt}(N$-hydroxybenzotriazole, $6 \mathrm{mg}, 0.044 \mathrm{mmol}, 1.8$ equiv.) in NMP ( $3 \mathrm{~mL}$ ) for $7 \mathrm{~min}$. Fmoc groups were removed by three successive treatments with $20 \%$ piperidine in NMP (3 mL) for 3 min. Peptidyl resin was extensively washed with DCM (dichloromethane) then dried under an air flow, and the crude peptide was deprotected and cleaved from the resin through a treatment with TFA/ $\mathrm{H}_{2} \mathrm{O} / i \mathrm{Pr}_{3} \mathrm{SiH} /$ phenol, 88:5:2:5 for $2 \mathrm{~h}$. The peptide was precipitated by dilution into an ice-cold diethyl ether/petroleum ether 1:1 mixture, recovered by centrifugation, and washed twice with diethyl ether and dried under reduced pressure.

Synthesis and physico-chemical characterization of pro3-SBP: The synthesis of the peptide was performed as described above to give crude peptide $\mathrm{H}$ eeeeeaaVADXADYQaarrrrrC- $\mathrm{NH}_{2}$, which was used without further purifications $(\mathrm{X}=$ norvaline, $\mathrm{L}$-amino acids are in uppercase and $\mathrm{D}$-amino acids in lowercase). The crude peptide $(2.65 \mathrm{mg}, 0.785 \mu \mathrm{mol}$, calculated from a molecular weight $(\mathrm{MW})=3377 \mathrm{~g} / \mathrm{mol}$ taking into account six trifluoroacetate counteranions) was dissolved in $500 \mu \mathrm{L}$ of 1 M HEPES buffer pH 7.5, deoxygenated through several successive vacuum ( $\sim 15 \mathrm{mbar}) /$ argon cycles in order to avoid cysteine oxidation. Then, a solution of sulfo-cyanine5.5 maleimide $(0.65 \mathrm{mg}, 0.877$ $\mu$ mol, 1.12 equiv.) in $100 \mu \mathrm{L}$ deoxygenated DMF was added under argon and the resulting mixture was further deoxygenated. After $13 \mathrm{~h}$ stirring at RT, a second portion of the maleimide reagent was added ( 1.12 equiv. in $100 \mu \mathrm{L}$ deoxygenated DMF), and the reaction was stirred for $30 \mathrm{~min}$. At this stage, HPLC analysis showed total consumption of the starting peptide material. 
A solution of QSY21 $\mathrm{N}$-hydroxy succinimide ester (1.28 mg, $1.570 \mu \mathrm{mol}, 2.0$ equiv.) in 100 $\mu \mathrm{L}$ DMF was then added, and the reaction was stirred for $1 \mathrm{~h}$, at RT. A second portion (1.76 equiv. in $88 \mu \mathrm{L}$ DMF) was then added and the reaction stirred for $18 \mathrm{~h}$. A third portion was added (2.24 equiv. in $112 \mu \mathrm{L} \mathrm{DMF}$ ) and the reaction stirred for an additional $6 \mathrm{~h}$. Reaction mixture was analyzed by HPLC to assess the completion of the reaction. The reaction was quenched by dilution into $5 \mathrm{~mL}$ of a $\mathrm{H}_{2} \mathrm{O} / \mathrm{MeCN} / \mathrm{TFA}$ 79.5:19.5:1 mixture then purified by semi-preparative HPLC and lyophilized to yield Pro3-SBP as a deep blue powder (37 nmol, determined by UV titration at $675 \mathrm{~nm}, \varepsilon=315100 \mathrm{M}^{-1} \cdot \mathrm{cm}^{-1}, 4.7 \%$ yield). Theoretical molecular absorption coefficient of pro3-SBP at $675 \mathrm{~nm}$ was calculated by addition of the reported one for sulfo-Cy5.5 at this wavelength $\left(\lambda_{\max }, \varepsilon=235000 \mathrm{M}^{-1} \cdot \mathrm{cm}^{-1}\right)^{\mathrm{a}}$ to the one determined for QSY21 $\left(\varepsilon^{675}=80100 \mathrm{M}^{-1} \cdot \mathrm{cm}^{-1}\right)$ from its absorption spectrum, ${ }^{\mathrm{b}}$ based on its reported $\varepsilon=89000$ $\mathrm{M}^{-1} \cdot \mathrm{cm}^{-1}$ at $\lambda_{\max }=660 \mathrm{~nm}$. Note that the conjugate showed limited solubility and tendency to precipitate under HPLC purification conditions, which explains the moderate (non-optimized) isolated yield. However, pro3-SBP is perfectly soluble and stable in a DMSO (dimethylsulfoxide) stock solution and does not show tendency to aggregate or precipitate under our in vitro or in cellulo tests conditions.

HPLC: semi-preparative purification gradient: $20-80 \% \mathrm{~B}$ over $30 \mathrm{~min}$, retention time $=19.8$ min. Analytical gradient: $20-80 \%$ B over $5 \mathrm{~min}$, retention time: $3.76 \mathrm{~min}$.

ESI-MS $(m / z)$ : $[\mathrm{M}+\mathrm{H}]^{3+}$ calcd. for $\mathrm{C}_{195} \mathrm{H}_{262} \mathrm{~N}_{47} \mathrm{O}_{58} \mathrm{~S}_{6}$ : 1461.6, found: $1461.4 ;[\mathrm{M}+2 \mathrm{H}]^{4+}$ calcd. for $\mathrm{C}_{195} \mathrm{H}_{263} \mathrm{~N}_{47} \mathrm{O}_{58} \mathrm{~S}_{6}$ : 1096.5 , found: 1096.2 . UV: $\lambda_{\max }=675.0 \mathrm{~nm}$ in $\mathrm{H}_{2} 0 / \mathrm{MeCN} / \mathrm{TFA}$ 70/30/0.1.

\section{Enzymes, inhibitors, reagents:}

Abz-Val-Ala-Asp-Nva-Ala-Asp-Tyr-Gln-EDDnp was synthetized according to Epinette et al. (2012). ${ }^{40}$ Synthesis of the peptidyl di(chlorophenyl)-phosphonate ester, BiotinylVal-Tyr-Asp-Nva-P(O-C $\left.\mathrm{C}_{6} \mathrm{H}_{4}-4-\mathrm{Cl}\right)_{2}$ was detailed elsewhere. ${ }^{26}$ Human PR3 (hPR3) was produced as reported earlier. ${ }^{49}$ Human neutrophil elastase (hNE) was provided by BioCentrum (Krakow, Poland). Human CatG was from ICN Pharmaceuticals (Costa Mesa, CA, USA). Human CatS was produced as previously described. ${ }^{50}$ Human CatD was provided by Merck KGaA (Darmstadt, Germany). Human cathepsins B, L, and $\mathrm{H}$ and human matrix metalloproteinases (MMP-8, MMP-9, MMP-12) were purchased from Calbiochem (VWR

\footnotetext{
${ }^{a}$ https://www.lumiprobe.com/p/sulfo-cy55-nhs-ester, last retrieved : 12/05/2021

${ }^{\mathrm{b}} \mathrm{https}$ ://www.aatbio.com/absorbance-uv-visible-spectrum-graph-viewer/, last retrieved : 12/05/2021
} 
International, Pessac, France). Brij35, EDTA, DTT and NP40 were obtained from SigmaAldrich (Saint Quentin Fallavier, France). Activity buffers were 0.05 M HEPES buffer, pH 7.4, $0.05 \% \mathrm{NP} 40,150 \mathrm{mM} \mathrm{NaCl}$ for hPR3, hNE, and CatG, $0.1 \mathrm{M}$ sodium citrate buffer, $\mathrm{pH} 4.0$ for aspartic CatD, 0.1 M sodium phosphate buffer, pH 7.4, 2 mM DTT, $1 \mathrm{mM}$ EDTA and 0.01\% Brij35 for CatS, $0.1 \mathrm{M}$ sodium acetate buffer, $\mathrm{pH}$ 5.5, containing 2 mM DTT, 1 mM EDTA and $0.01 \%$ Brij 35 for cathepsins $\mathrm{B}, \mathrm{H}$, and $\mathrm{L}$, and $0.05 \mathrm{M}$ Tris buffer, $\mathrm{pH} 7.5$, containing $0.05 \%$ Brij35, $150 \mathrm{mM} \mathrm{NaCl}$, and $10 \mathrm{mM} \mathrm{CaCl}_{2}$ for MMP-8, MMP-9, and MMP-12, respectively.

\section{Preparation of human neutrophils:}

Blood samples were collected from healthy volunteers by the "Etablissement Français du Sang Centre-Pays de Loire" (EFS Tours, France). Specimens were delivered by EFS (University of Tours/EFS agreement) in accordance with ethical rules (approval number \#CPDL-PLER-2019 188). Neutrophils were isolated from EDTA-whole blood by negative magnetic selection using the "EasySep Direct Human Neutrophil Isolation Kit" (Stemcell Technologies, Cambridge, UK).

\section{Characterization of the NIRF probe (pro3-SBP):}

Kinetics parameters of pro3-SBP: hPR3 $(10 \mathrm{nM})$ was incubated for $5 \mathrm{~min}$ at $37^{\circ} \mathrm{C}$ in the assay buffer prior addition of pro3-SBP ( $1 \mu \mathrm{M}$ final concentration). Determination of the second-order rate constants $\left(\mathrm{k}_{\mathrm{cat}} / \mathrm{K}_{\mathrm{m}}\right)$ were carried out under pseudo first-order conditions. The enzymatic activity was followed by monitoring the hydrolysis of pro3-SBP ( $\lambda_{\mathrm{ex}}: 684 \mathrm{~nm}$; $\lambda_{\mathrm{em}}$ : $710 \mathrm{~nm}$ ) (Cary Eclipse spectrofluorimeter, Agilent Technologies, Les Ulis, France). The halftime of the reaction $\left(\mathrm{t}_{1 / 2}\right)$ was obtained graphically by plotting $[\mathrm{P}]=\mathrm{f}(\mathrm{t})$, with $\mathrm{k}_{\mathrm{obs}}=\ln 2 / \mathrm{t}_{1 / 2}$. The value of $\mathrm{k}_{\mathrm{cat}} / \mathrm{K}_{\mathrm{m}}\left(\mathrm{M}^{-1} \cdot \mathrm{s}^{-1}\right)$ was deduced from the equation $\mathrm{k}_{\mathrm{cat}} / \mathrm{K}_{\mathrm{m}}=\mathrm{k}_{\mathrm{obs}} /[\mathrm{E}](\mathrm{GraphPad}$ Prism 6, San Diego, CA, USA). Kinetic data were reported as means \pm S.D (three independent experiments). The maximal velocity of the reaction $\left(\mathrm{V}_{\max }\right)$ and the Michaelis constant $\left(\mathrm{K}_{\mathrm{m}}\right)$ were fitted from initial velocity measurements (GraphPad Prism 6), by varying pro3-SBP concentrations $(0.5-8 \mu \mathrm{M})$ for a constant hPR3 concentration $(5 \mathrm{nM})(\mathrm{n}=3)$. The same experience was repeated in the presence of hHNE.

Selectivity of pro3-SBP: Pro3-SBP selectivity was checked by incubating proteases $(10 \mathrm{nM}) 5 \mathrm{~min}$ at $37^{\circ} \mathrm{C}$ in their respective activity buffer prior addition of pro3-SBP $(1 \mu \mathrm{M})$. Enzymatic activity was recorded by monitoring the fluorescence release $\left(\lambda_{\text {ex }}: 684 \mathrm{~nm} ; \lambda_{\mathrm{em}}: 710\right.$ $\mathrm{nm})$ (Cary Eclipse spectrofluorimeter). On the other hand, pro3-SBP $(1 \mu \mathrm{M})$ was incubated with hPR3 for $30 \mathrm{~min}$ at $37{ }^{\circ} \mathrm{C}$ in its assay buffer (final volume: $100 \mu \mathrm{L}$ ). The reaction was 
stopped by addition of ethanol $(500 \mu \mathrm{L})$. After centrifugation $\left(6,000 \mathrm{rpm} / 10 \mathrm{~min}, 4{ }^{\circ} \mathrm{C}\right)$, the precipitate was removed and the native peptide and/or its proteolytic fragments was evaporated to dryness and re-dissolved in water containing $0.1 \%$ trifluoroacetic acid. Proteolysis products were separated by reverse-phase chromatography (Brownlee Aquapore RP-300, C8 Phase Cartridge Column, PerkinElmer), using a 41-min linear (0-90\%) gradient of acetonitrile in water $(0.1 \%$ TFA) at a flow rate of $0.5 \mathrm{~mL} / \mathrm{min}$ (P1000XR, SpectraSystem), and analyzed by the ChromQuest chromatography Workstation (ThermoFinnigan, Les Ulis, France). The same experiment was conducted for $\mathrm{hNE}, \mathrm{CatG}$ and CatS $(10 \mathrm{nM})$ in their respective assay buffer. Identification of cleavage sites were performed by analysis of the hydrolysis products by MALDI-TOF mass spectrometry (MALDI-TOF/TOF UltraFleXtreme, Bruker Daltonics). QSY21-eeeeeaaVADX-OH $\quad(\mathrm{X}=$ norvaline $) \quad(\mathrm{m} / \mathrm{z})$ : monoisotopic $[\mathrm{M}]^{+}$calculated for $\mathrm{C}_{89} \mathrm{H}_{109} \mathrm{~N}_{14} \mathrm{O}_{28} \mathrm{~S}: 1853.73$, found: 1853.72. QSY21-eeeeeaaVADXA-OH (X=norvaline) $(\mathrm{m} / \mathrm{z}$, monoisotopic): $[\mathrm{M}]^{+}$calculated for $\mathrm{C}_{92} \mathrm{H}_{114} \mathrm{~N}_{15} \mathrm{O}_{29} \mathrm{~S}:$ 1924.76, found: 1924.75. HADYQaarrrrrC(sulfoCy5.5)- $\mathrm{NH}_{2}$ ( $m / z$, monoisotopic): $[\mathrm{M}]^{+}$calculated for $\mathrm{C}_{106} \mathrm{H}_{154} \mathrm{~N}_{33} \mathrm{O}_{31} \mathrm{~S}_{5}$ : 2545.01, found: 2545.00. H-DYQaarrrrrC(sulfoCy5.5)- $\mathrm{NH}_{2}$ ( $\mathrm{m} / z$, monoisotopic): [M] ${ }^{+}$ calculated for $\mathrm{C}_{103} \mathrm{H}_{149} \mathrm{~N}_{32} \mathrm{O}_{30} \mathrm{~S}_{5}: 2473.97$, found: 2473.95 .

Physicochemical properties of pro3-SBP: The stability of pro3-SBP $(1 \mu \mathrm{M})$ in an aqueous buffer was endorsed by incubation for $0-60 \mathrm{~min}$ at $37^{\circ} \mathrm{C}$ in its assay buffer (final volume: $100 \mu \mathrm{L})$ as reported elsewhere. ${ }^{46}$ Alternatively, after addition of ethanol $(500 \mu \mathrm{L})$, centrifugation $\left(6,000 \mathrm{rpm} / 10 \mathrm{~min}, 4^{\circ} \mathrm{C}\right)$ and evaporation to dryness, integrity of pro3-SBP was checked by RP-HPLC (Brownlee Aquapore RP-300) using conditions reported above (ChromQuest chromatography Workstation). Moreover, the possible hazard of an intermolecular fluorescence quenching associated to pro3-SBP hydrolysis and the subsequent release of intramolecular sulfoCy5.5/QSY21 couple was evaluated by incubation of hPR3 (5 $\mathrm{nM})$ with increasing amounts of the probe $(0-8 \mu \mathrm{M})$ at $37^{\circ} \mathrm{C}$ in the assay buffer $\left(\lambda_{\text {ex }}: 684 \mathrm{~nm}\right.$; $\left.\lambda_{\mathrm{em}}: 710 \mathrm{~nm}\right)$.

Detection threshold of pro3-SBP: Increasing amounts of hPR3 (0-5 nM) were incubated in the presence of pro3-SBP $(0.5 \mu \mathrm{M})$ in 0.05 M HEPES buffer, $\mathrm{pH} 7.4,0.05 \%$ NP40, $150 \mathrm{mM} \mathrm{NaCl}$ (black 96-well microtiter plates, Nunc, ThermoFisher Scientific, Villebon-surYvette, France). After $5 \mathrm{~min}$, fluorescence release was measured using IVIS Caliper Lumina XR imaging system (10 s exposure, Caliper LifeSciences, Villepinte, France) $\left(\lambda_{\text {ex: }} 640 \mathrm{~nm} ; \lambda_{\text {em: }}\right.$ : $675 \mathrm{~nm}$ ). Data were presented on color scale overlaid on a grayscale photograph (microplate wells). They were quantified as total radiant efficiency (photons (p) per second (s) per $\mathrm{cm}^{2}$ per steradian $\left.(\mathrm{sr})\left[\mathrm{photons} / \mathrm{s} / \mathrm{cm}^{2} / \mathrm{sr}\right]\right)$ within a circular region of interest $\left(1 \times 10^{3}\right.$ pixels) using the 
Living Image 4.3.1 software (Caliper Life Sciences). ${ }^{46}$ Similarly, hPR3 (5 nM) was incubated in the presence of increasing concentrations of pro3-SBP $(0-5 \mu \mathrm{M})$, before recording the fluorescence release $(\mathrm{t}=0$-25 $\mathrm{min})$. Assay was repeated by pre-incubating hPR3 $(5 \mathrm{nM})$ in the presence of a hPR3 inhibitor, Biotinyl-Val-Tyr-Asp-Nva-P(O- $\left.\mathrm{C}_{6} \mathrm{H}_{4}-4-\mathrm{Cl}\right)_{2}(10 \mu \mathrm{M})^{26}$, prior addition of pro3-SBP $(5 \mu \mathrm{M})$ and recording of the fluorescence release 10 min latter. On the other hand, purified neutrophils $\left(5 \times 10^{6}\right.$ neutrophils) were activated by ionomycin, a calcium ionophore ( $1 \mu \mathrm{M}$, Sigma-Aldrich), for $20 \mathrm{~min}$ at $37^{\circ} \mathrm{C}$ in phosphate-buffered saline $/ 1 \mathrm{mM}$ $\mathrm{CaCl}_{2} / 1 \mathrm{mM} \mathrm{MgCl} 2$ (final volume: $5 \mathrm{~mL}$ ). Then, 500,000 neutrophils/well were seeded in 96well plates at $37^{\circ} \mathrm{C}\left(5 \% \mathrm{CO}_{2}\right)$ in Gibco free-fetal calf serum RPMI-1640 medium (Fisher Scientific, Illkrich, France) for $24 \mathrm{~h}$. Cell supernatants were collected and the fluorescence release was monitored (IVIS Caliper Lumina XR imaging system, $t=0-30 \mathrm{~min}$ ), following addition of pro3-SBP $(5 \mu \mathrm{M})$. Controls were carried out in the presence of quiescent PMNs, and selectivity of NIRF signal was checked by addition of a hPR3 inhibitor, Biotinyl-Val-TyrAsp-Nva-P(O-C $\left.6 \mathrm{H}_{4}-4-\mathrm{Cl}\right)_{2}(1 \mu \mathrm{M})$.

\section{Activation of human neutrophils: imaging by confocal microscopy:}

Following their isolation, purified neutrophils $\left(5 \times 10^{6}\right.$ neutrophils $)$ were immediately stimulated with phosphate-buffered saline/1 mM CaCl$/ 1 \mathrm{mM} \mathrm{MgCl}_{2}$, containing $250 \mathrm{nM}$ ionomycin for $20 \mathrm{~min}$ at $37^{\circ} \mathrm{C}$ (final volume: $5 \mathrm{~mL}$ ). Then, cells $(500,000$ neutrophils/well) were seeded in 96-well Well Black ibiTreat microplates (Ibidi, CliniSciences, Nanterre, France) at $37^{\circ} \mathrm{C}\left(5 \% \mathrm{CO}_{2}\right)$ in Gibco FCS-free RPMI-1640 medium for $4 \mathrm{~h}$. After removal of nonadherent cells, pro3-SBP $(10 \mu \mathrm{M})$ was immediately added to the culture medium and imaging performed by confocal fluorescence microscopy (Leica SP8 Confocal Microscope, Leica Microsystèmes, Nanterre, France) (0-15 min.). Data were acquired using White Light Laser (Cys5.5; wavelength $675 \mathrm{~nm}$ ) and transmitted light detector (diode 405; wavelength 405nm) with constant microscope settings (laser power, detector gain, and amplification offset). Assays were repeated with non-activated (quiescent) neutrophils. Alternatively, a control experiment was conducted; cell media of both quiescent and activated neutrophils were withdrawn and hPR3 activity was monitored using Abz-Val-Ala-Asp-Nva-Ala-Asp-Tyr-Gln- EDDnp (20 $\mu \mathrm{M})$ as substrate in $0.05 \mathrm{M}$ HEPES, $0.75 \mathrm{M} \mathrm{NaCl}$, and $0.05 \%$ NP40, pH 7.4 (spectromicrofluorimeter SpectraMax Gemini, Molecular Devices, Saint Grégoire, France; $\left.\lambda_{\mathrm{ex}}=320 \mathrm{~nm}, \lambda_{\mathrm{em}}=420 \mathrm{~nm}\right)$. Selectivity of substrate was checked by adding Biotinyl-Val-TyrAsp-Nva-P(O-C $\left.\mathrm{C}_{4}-4-\mathrm{Cl}\right)_{2}(1 \mu \mathrm{M})$. Experiments were performed in triplicate. 


\section{Cell viability assay:}

CellTiter 96® AQueous One Solution Cell Proliferation Assay (3-(4,5-dimethylthiazol2-yl)-5-(3-carboxymethoxyphenyl)-2-(4-sulfophenyl)-2H-tetrazolium, MTS) kit (Promega, Charbonnière-Les-Bains, France) was used to evaluate cytotoxicity of pro3-SBP, according to the manufacturer's instructions. Briefly, both ionomycin-treated and untreated neutrophils (500,000 cells/well) were cultured for $4 \mathrm{~h}$ in 96-well plates containing $100 \mu \mathrm{L}$ of medium as described above. At various time $(0,5$, and $15 \mathrm{~min})$, pro3-SBP $(10 \mu \mathrm{M})$ was incubated with culture medium at $37^{\circ} \mathrm{C}\left(5 \% \mathrm{CO}_{2}\right)$. The MTS reagent was added $(20 \mu \mathrm{L} /$ well $)$ and cells were incubated under the same conditions for $2 \mathrm{~h}$. The absorbance was measured at $490 \mathrm{~nm}$ (Microplate Reader VersaMAx, Molecular Devices, St Grégoire, France). All the experiments were repeated three times. MTS assay results were normalized using as reference the proliferation rate of quiescent neutrophils in the absence of pro3-SBP (control value defined as $100 \%$ ). Assays were performed in triplicate.

\section{Statistical analysis:}

Data are expressed as means \pm standard deviation (SD). Statistical significance between the different values was analyzed by nonparametric Mann-Whitney $U$ test and group comparisons were performed with nonparametric Kruskal-Wallis test. Statistical analysis was performed using GraphPad Prism v8.4.2 (San Diego, CA, USA). Differences at a $P$-value < 0.05 were considered significant $(* *: P<0.005 ; * * *: P<0.0005)$.

\section{Supporting Information:}

Figure S1. Characterization of purified pro3-SBP (HPLC trace, UV-vis and ESI-MS spectra)

Figure S2. Cleavage of pro3-SBP by hPR3.

Figure S3. Cleavage of pro3-SBP by hNE.

Figure S4. Cell viability assay. 
Acknowledgments: We acknowledge Dr Guillaume Gabant (mass spectrometry platform of CBM (Center for Molecular Biophysics, Orléans, France) and Julien Burlaud-Gaillard (IBiSA electron microscopy platform, Université de Tours, Tours, France) for their invaluable technical assistance. The graphical abstract was created using BioRender.com.

Funding: This work was supported by la Région Centre-Val de Loire, France (Pirana project; number 2019-00134916). We acknowledge the Institut National de la Santé et de la Recherche Médicale (INSERM), the Centre National de la Recherche Scientifique (CNRS) and the University of Tours for institutional funding. These agencies played no role in study design, data collection and analysis, the decision to publish or preparation of the manuscript.

Competing interests: The authors declare that they have no competing interests.

Abbreviations: Abz, o-aminobenzoic acid; AMC, 7-amino-4-methyl coumarin; ARDS, acute respiratory distress syndrome ; Brij35, polyethylene glycol lauryl ether; CatB, cathepsin B; CatD, cathepsin D; CatG, cathepsin G; CatH, cathepsin H; CatL, cathepsin L; CatS, cathepsin $\mathrm{S}$; CPP, cell-penetrating peptide; COPD, chronic obstructive pulmonary disease; DMF, dimethylfomamide; DTT; dithiothreitol; EDDnp, $N$-(2.4-dinitrophenyl)ethylenediamine; FCS, fetal calf serum; FRET, fluorescence resonance energy transfer; HEPES, 4-(2-hydroxyethyl)1-piperazineethanesulfonic acid; hNE, human neutrophil elastase; Fmoc, fluorenylmethyloxycarbonyl; IL-8, interleukin 8; IL-1 $\beta$, interleukin-1 beta; MALDI-TOF, matrix assisted laser desorption ionization time-of-flight; $\mathrm{MeCN}$, acetonitrile ; MMP-8, matrix metalloproteinase-8; MMP-9, matrix metalloproteinase-9, MMP-12, matrix metalloproteinase12; MTS, 3-(4,5-dimethylthiazol-2-yl)-5-(3-carboxymethoxyphenyl)-2-(4-sulfophenyl)-2Htetrazolium; NHS, N-hydroxysuccinimide; NIRF, near infrared fluorescence; NP40, nonyl phenoxypolyethoxylethanol; NSP, neutrophil serine protease; NMP, N-methyl-2-pyrrolidone; Pbf, pentamethyldihydrobenzofuran-5-sulfonyl; PMN, polymorphonuclear neutrophil; hNE, human neutrophil elastase; hPR3, human proteinase 3; RP-HPLC, reversed phase high performance liquid chromatography; SPPS, solid phase peptide synthesis; TFA, trifluoroacetic acid; TNF- $\alpha$, tumor necrosis factor alpha ; Trt, trityl. 


\section{References}

(1) Pham, C. T. N. (2006) Neutrophil serine proteases: specific regulators of inflammation. Nat. Rev. Immunol. 6, 541-550.

(2) Korkmaz, B., Horwitz, M. S., Jenne, D. E., and Gauthier, F. (2010) Neutrophil elastase, proteinase 3, and cathepsin $\mathrm{G}$ as therapeutic targets in human diseases. Pharmacol. Rev. $62,726-759$.

(3) Perera, N. C., Schilling, O., Kittel, H., Back, W., Kremmer, E., and Jenne, D. E. (2012) NSP4, an elastase-related protease in human neutrophils with arginine specificity. Proc Natl. Acad. Sci. U. S. A. 109, 6229-6234.

(4) AhYoung, A. P., Lin, S. J., Gerhardy, S., van Lookeren Campagne, M., and Kirchhofer, D. (2019) An ancient mechanism of arginine-specific substrate cleavage: What's "up" with NSP4? Biochimie 166, 19-26.

(5) Korkmaz, B., Caughey, G. H., Chapple, I., Gauthier, F., Hirschfeld, J., Jenne, D. E., Kettritz, R., Lalmanach, G., Lamort, A.-S., Lauritzen, C., et al. (2018) Therapeutic targeting of cathepsin C: from pathophysiology to treatment. Pharmacol. Ther. 190, 202236.

(6) Owen, C. A. (2008) Roles for proteinases in the pathogenesis of chronic obstructive pulmonary disease. Int. J. Chron. Obstruct. Pulmon. Dis. 3, 253-268.

(7) Korkmaz, B., Moreau, T., and Gauthier, F. (2008) Neutrophil elastase, proteinase 3 and cathepsin G: physicochemical properties, activity and physiopathological functions. Biochimie 90, 227-242.

(8) Brinkmann, V., Reichard, U., Goosmann, C., Fauler, B., Uhlemann, Y., Weiss, D.S., Weinrauch, Y. and Zychlinsky, A. (2004) Neutrophil extracellular traps kill bacteria. Science 303, 1532-1535.

(9) Witko-Sarsat, V., Cramer, E.M., Hieblot, C., Guichard, J., Nusbaum, P., Lopez, S., Lesavre, P. and Halbwachs-Mecarelli, L. (1999) Presence of proteinase 3 in secretory vesicles: evidence of a novel, highly mobilizable intracellular pool distinct from azurophil granules. Blood 94, 2487-2496.

(10) Weiss, S. A. I., Rehm, S. R. T., Perera, N. C., Biniossek, M. L., Schilling, O., and Jenne, D. E. (2021) Origin and Expansion of the Serine Protease Repertoire in the Myelomonocyte Lineage. Int. J. Mol. Sci. 22.

(11) Sørensen, O. E., Follin, P., Johnsen, A. H., Calafat, J., Tjabringa, G. S., Hiemstra, P. S., and Borregaard, N. (2001) Human cathelicidin, hCAP-18, is processed to the antimicrobial peptide LL-37 by extracellular cleavage with proteinase 3. Blood 97, 39513959.

(12) Renesto, P., Halbwachs-Mecarelli, L., Nusbaum, P., Lesavre, P., and Chignard, M. (1994) Proteinase 3. A neutrophil proteinase with activity on platelets. J. Immunol. 152, 46124617. 
(13) Sköld, S., Rosberg, B., Gullberg, U., and Olofsson, T. (1999) A secreted proform of neutrophil proteinase 3 regulates the proliferation of granulopoietic progenitor cells. Blood $93,849-856$.

(14) Yang, M., Li, K., Lam, A. C., Yuen, P. M., Fok, T. F., Chesterman, C. N., and Chong, B. H. (2001) Platelet-derived growth factor enhances granulopoiesis via bone marrow stromal cells. Int. J. Hematol. 73, 327-334.

(15) Lüdemann, J., Utecht, B., and Gross, W. L. (1990) Anti-neutrophil cytoplasm antibodies in Wegener's granulomatosis recognize an elastinolytic enzyme. J. Exp. Med. 171, 357362.

(16) Hedstrom, L. (2002) Serine protease mechanism and specificity. Chem. Rev. 102, 45014524.

(17) Fujinaga, M., Chernaia, M. M., Halenbeck, R., Koths, K., and James, M. N. (1996) The crystal structure of PR3, a neutrophil serine proteinase antigen of Wegener's granulomatosis antibodies. J. Mol. Biol. 261, 267-278.

(18) Bode, W., Wei, A. Z., Huber, R., Meyer, E., Travis, J., and Neumann, S. (1986) X-ray crystal structure of the complex of human leukocyte elastase (PMN elastase) and the third domain of the turkey ovomucoid inhibitor. The EMBO J. 5, 2453-2458.

(19) Korkmaz, B., Attucci, S., Moreau, T., Godat, E., Juliano, L., and Gauthier, F. (2004) Design and use of highly specific substrates of neutrophil elastase and proteinase 3. Am. J. Respir. Cell. Mol. Biol. 30, 801-807.

(20) Korkmaz, B., Kellenberger, C., Viaud-Massuard, M.-C., and Gauthier, F. (2013) Selective inhibitors of human neutrophil proteinase 3. Curr. Pharm. Des. 19, 966-976.

(21) Korkmaz, B., Lesner, A., Guarino, C., Wysocka, M., Kellenberger, C., Watier, H., Specks, U., Gauthier, F. and Jenne, D.E. (2016) Inhibitors and Antibody Fragments as Potential Anti-Inflammatory Therapeutics Targeting Neutrophil Proteinase 3 in Human Disease. Pharmacol. Rev. 68, 603-630.

(22) Popow-Stellmaszyk, J., Wysocka, M., Lesner, A., Korkmaz, B., and Rolka, K. (2013) A new proteinase 3 substrate with improved selectivity over human neutrophil elastase. Anal. Biochem. 442, 75-82.

(23) Edgington, L. E., Verdoes, M., and Bogyo, M. (2011) Functional imaging of proteases: recent advances in the design and application of substrate-based and activity-based probes. Curr. Opin. Chem. Biol. 15, 798-805.

(24) Sanman, L. E., and Bogyo, M. (2014) Activity-based profiling of proteases. Annu. Rev. Biochem. 83, 249-273.

(25) Vizovišek, M., Fonović, M., and Turk, B. (2018) Cysteine cathepsins in extracellular matrix remodeling: Extracellular matrix degradation and beyond. Matrix Biol. 75-76, 141-159. 
(26) Guarino, C., Gruba, N., Grzywa, R., Dyguda-Kazimierowicz, E., Hamon, Y., Łȩgowska, M., Skoreński, M., Dallet-Choisy, S., Marchand-Adam, S., Kellenberger, C., et al. (2018) Exploiting the S4-S5 Specificity of Human Neutrophil Proteinase 3 to Improve the Potency of Peptidyl Di(chlorophenyl)-phosphonate Ester Inhibitors: A Kinetic and Molecular Modeling Analysis. J. Med. Chem. 61, 1858-1870.

(27) Kasperkiewicz, P., Poreba, M., Snipas, S. J., Parker, H., Winterbourn, C. C., Salvesen, G. S., and Drag, M. (2014) Design of ultrasensitive probes for human neutrophil elastase through hybrid combinatorial substrate library profiling. Proc. Natl. Acad. Sci. U. S. A. $111,2518-2523$.

(28) Kasperkiewicz, P., Poreba, M., Snipas, S. J., Lin, S. J., Kirchhofer, D., Salvesen, G. S., and Drag, M. (2015) Design of a Selective Substrate and Activity Based Probe for Human Neutrophil Serine Protease 4. PloS One 10, e0132818.

(29) Kasperkiewicz, P., Altman, Y., D’Angelo, M., Salvesen, G. S., and Drag, M. (2017) Toolbox of Fluorescent Probes for Parallel Imaging Reveals Uneven Location of Serine Proteases in Neutrophils. J. Am. Chem. Soc. 139, 10115-10125.

(30) Kasperkiewicz, P., Poreba, M., Groborz, K., and Drag, M. (2017) Emerging challenges in the design of selective substrates, inhibitors and activity-based probes for indistinguishable proteases. FEBS J. 284, 1518-1539.

(31) Guarino, C., Legowska, M., Epinette, C., Kellenberger, C., Dallet-Choisy, S., Sieńczyk, M., Gabant, G., Cadene, M., Zoidakis, J., Vlahou, A., et al. (2014) New selective peptidyl di(chlorophenyl) phosphonate esters for visualizing and blocking neutrophil proteinase 3 in human diseases. J. Biol. Chem. 289, 31777-31791.

(32) Anderson, B.M., Poole, D.P., Aurelio, L., Ng, G.Z., Fleischmann, M., Kasperkiewicz, P., Morissette, C., Drag, M., van Driel, I.R., Schmidt, B.L., et al. (2019) Application of a chemical probe to detect neutrophil elastase activation during inflammatory bowel disease. Sci. Rep. 9, 13295.

(33) Poreba, M., Groborz, K.M., Rut, W., Pore, M., Snipas, S.J., Vizovisek, M., Turk, B., Kuhn, P., Drag, M. and Salvesen, G.S. (2020) Multiplexed Probing of Proteolytic Enzymes Using Mass Cytometry-Compatible Activity-Based Probes. J. Am. Chem. Soc. 142, 16704-16715.

(34) Burster, T., Gärtner, F., Knippschild, U., and Zhanapiya, A. (2021) Activity-Based Probes to Utilize the Proteolytic Activity of Cathepsin G in Biological Samples. Front. Chem. 9, 628295 .

(35) Vizovišek, M., Vidmar, R., Drag, M., Fonović, M., Salvesen, G. S., and Turk, B. (2018) Protease Specificity: Towards In Vivo Imaging Applications and Biomarker Discovery. Trends Biochem. Sci.43, 829-844.

(36) Kasperkiewicz, P. (2021) Peptidyl Activity-Based Probes for Imaging Serine Proteases. Front. Chem. 9, 639410.

(37) Frey, D. L., Guerra, M., Mall, M. A., and Schultz, C. (2021) Monitoring Neutrophil Elastase and Cathepsin G Activity in Human Sputum Samples. J. Vis. Exp. (171). 
(38) Korkmaz, B., Attucci, S., Juliano, M. A., Kalupov, T., Jourdan, M.-L., Juliano, L., and Gauthier, F. (2008) Measuring elastase, proteinase 3 and cathepsin G activities at the surface of human neutrophils with fluorescence resonance energy transfer substrates. Nat. Protoc. 3, 991-1000.

(39) Jiang, T., Olson, E. S., Nguyen, Q. T., Roy, M., Jennings, P. A., and Tsien, R. Y. (2004) Tumor imaging by means of proteolytic activation of cell-penetrating peptides. Proc. Natl. Acad. Sci. U. S. A. 101, 17867-17872.

(40) Epinette, C., Croix, C., Jaquillard, L., Marchand-Adam, S., Kellenberger, C., Lalmanach, G., Cadene, M., Viaud-Massuard, M.-C., Gauthier, F. and Korkmaz, B. (2012) A selective reversible azapeptide inhibitor of human neutrophil proteinase 3 derived from a high affinity FRET substrate. Biochem. Pharmacol. 83, 788-796.

(41) Chin, J., and Kim, H.-J. (2018) Near-infrared fluorescent probes for peptidases. Coord. Chem. Rev. 354, 169-181.

(42) Futaki, S., Suzuki, T., Ohashi, W., Yagami, T., Tanaka, S., Ueda, K., and Sugiura, Y. (2001) Arginine-rich peptides. An abundant source of membrane-permeable peptides having potential as carriers for intracellular protein delivery. J. Biol. Chem. 276, 58365840 .

(43) Bechara, C., and Sagan, S. (2013) Cell-penetrating peptides: 20 years later, where do we stand? FEBS lett. 587, 1693-1702.

(44) Mitchell, D. J., Kim, D. T., Steinman, L., Fathman, C. G., and Rothbard, J. B. (2000) Polyarginine enters cells more efficiently than other polycationic homopolymers. J. Pept. Res. 56, 318-325.

(45) Walrant, A., Cardon, S., Burlina, F., and Sagan, S. (2017) Membrane Crossing and Membranotropic Activity of Cell-Penetrating Peptides: Dangerous Liaisons? Acc. Chem. Res. 50, 2968-2975.

(46) Wartenberg, M., Saidi, A., Galibert, M., Joulin-Giet, A., Burlaud-Gaillard, J., Lecaille, F., Scott, C.J., Aucagne, V., Delmas, A.F. and Lalmanach, G. (2019) Imaging of extracellular cathepsin $\mathrm{S}$ activity by a selective near infrared fluorescence substrate-based probe. Biochimie 166, 84-93.

(47) Fukuda, T., Ackerman, S. J., Reed, C. E., Peters, M. S., Dunnette, S. L., and Gleich, G. J. (1985) Calcium ionophore A23187 calcium-dependent cytolytic degranulation in human eosinophils. J. Immunol. 135, 1349-1356.

(48) Hoppenbrouwers, T., Autar, A.S.A., Sultan, A.R., Abraham, T.E., van Cappellen, W.A., Houtsmuller, A.B., van Wamel, W.J.B., van Beusekom, H.M.M., van Neck, J.W. and de Maat, M.P.M. (2017) In vitro induction of NETosis: Comprehensive live imaging comparison and systematic review. PLoS ONE 12, e 0176472.

(49) Jégot, G., Derache, C., Castella, S., Lahouassa, H., Pitois, E., Jourdan, M.L., RemoldO’Donnell, E., Kellenberger, C., Gauthier, F. and Korkmaz, B. (2011) A substrate-based approach to convert SerpinB1 into a specific inhibitor of proteinase 3, the Wegener's granulomatosis autoantigen. FASEB J. 25, 3019-3031. 
(50) Sage, J., Leblanc-Noblesse, E., Nizard, C., Sasaki, T., Schnebert, S., Perrier, E., Kurfurst, R., Brömme, D., Lalmanach, G. and Lecaille, F. (2012) Cleavage of nidogen-1 by cathepsin S impairs its binding to basement membrane partners. PloS One 7, e43494.

\section{Footnotes:}

${ }^{a}$ https://www.lumiprobe.com/p/sulfo-cy55-nhs-ester, last retrieved: 12/05/2021

${ }^{\mathrm{b}} \mathrm{https}$ ://www.aatbio.com/absorbance-uv-visible-spectrum-graph-viewer/, last retrieved: $12 / 05 / 2021$

\section{Table of Contents graphic (TOC):}

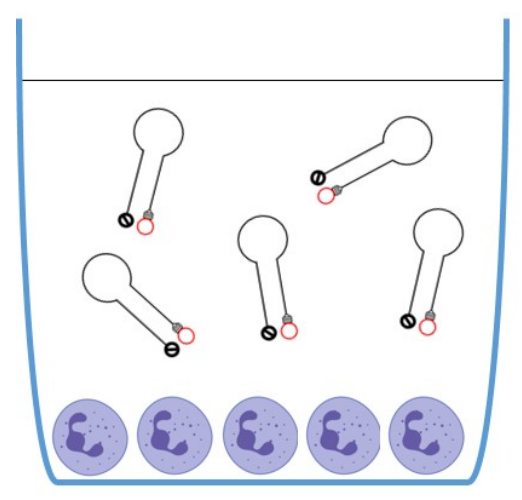

Quiescent neutrophils

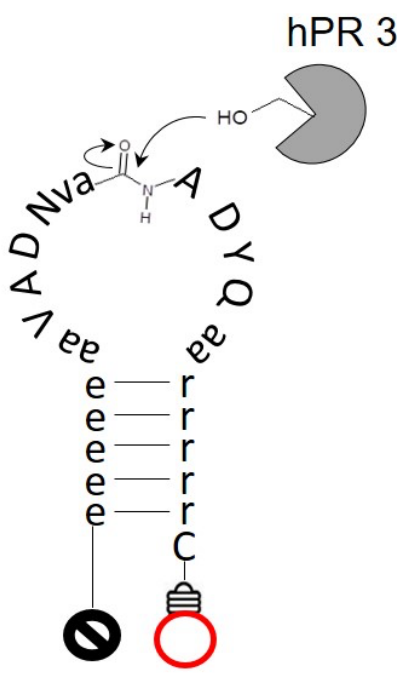

Pro3-SBP

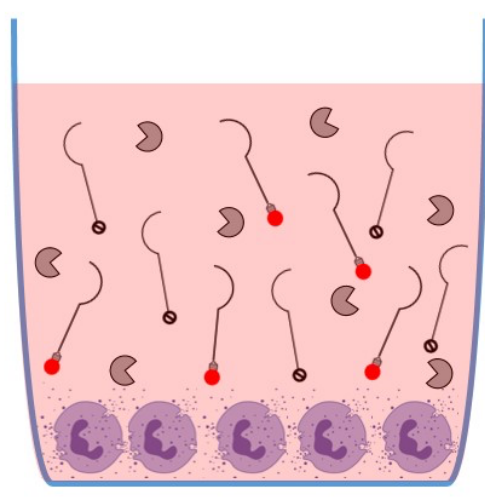

Activated neutrophils 
a)

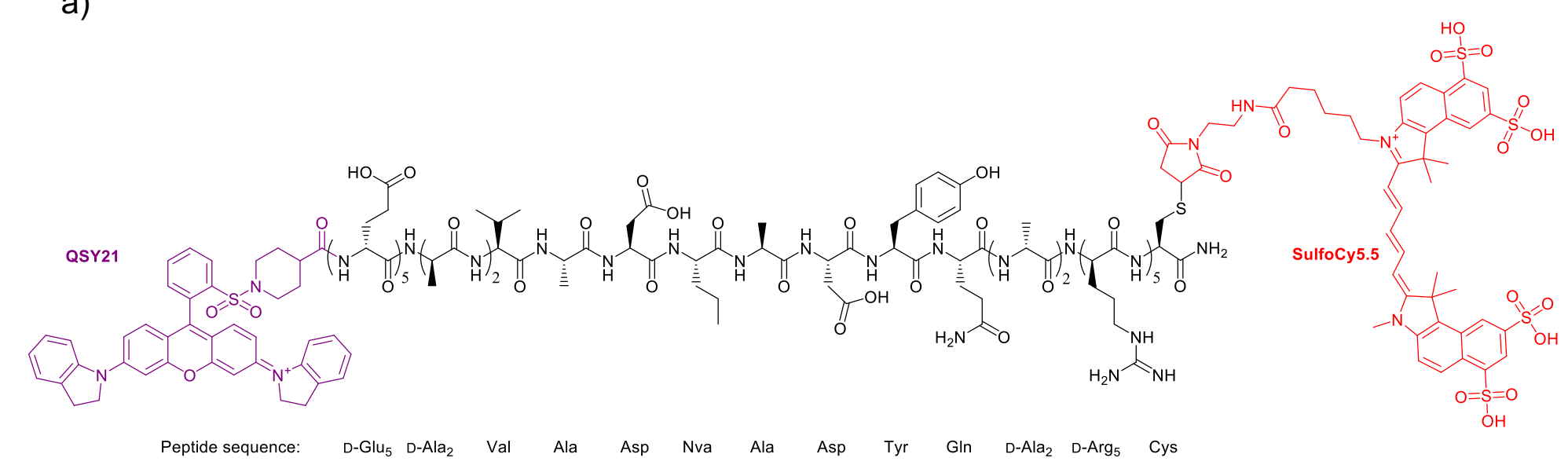

b)

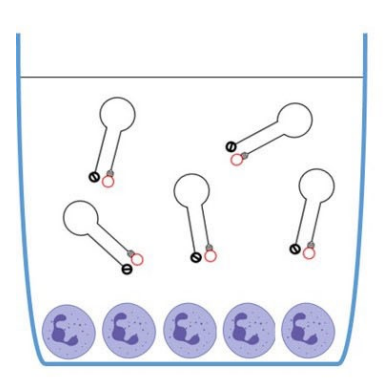

Quiescent neutrophils

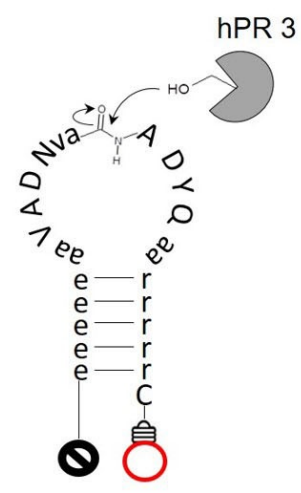

Pro3-SBP

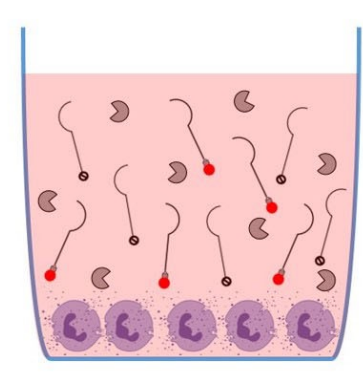

Activated neutrophils

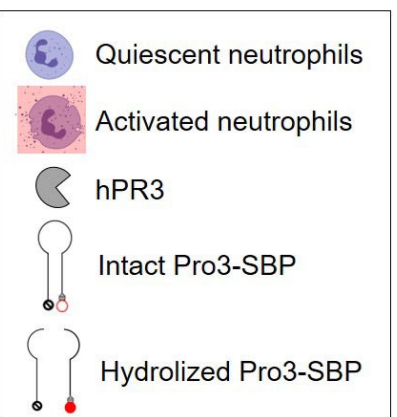


a)

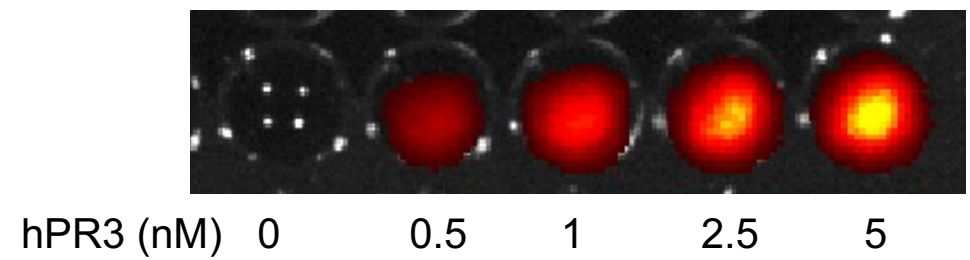

b)

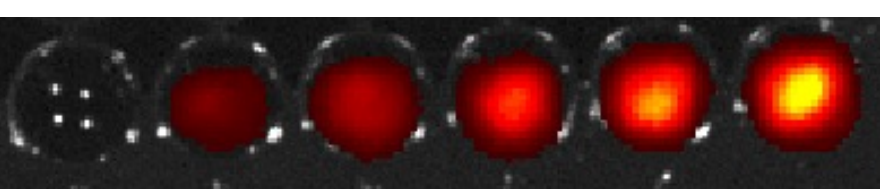

Pro3-SBP $(\mu \mathrm{M}) \quad 0 \quad 0.25$

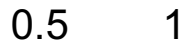

2

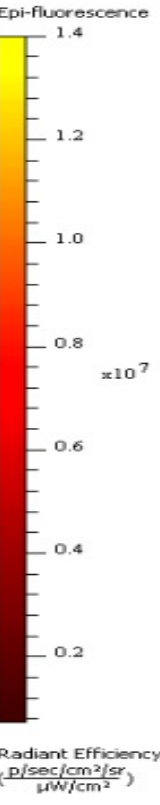

c)

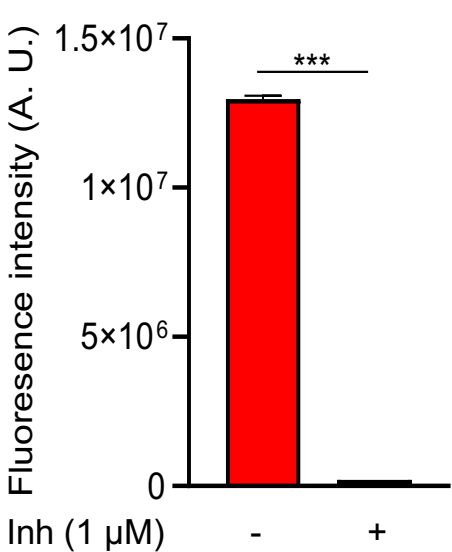

d)

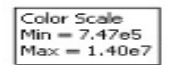

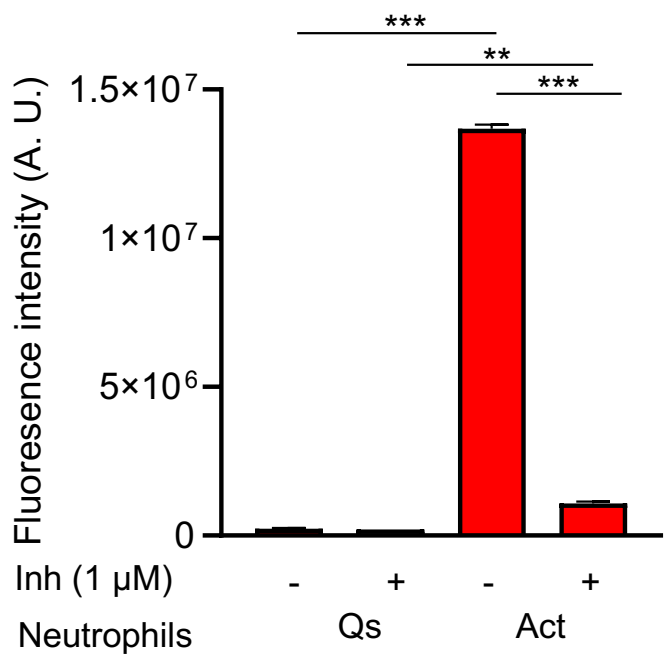


a)

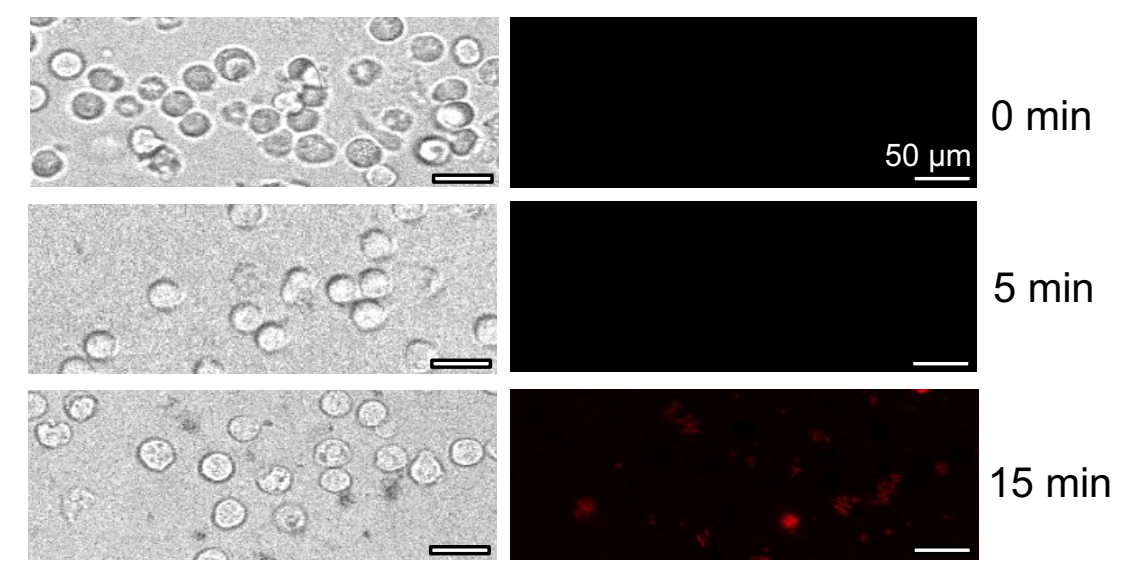

b)

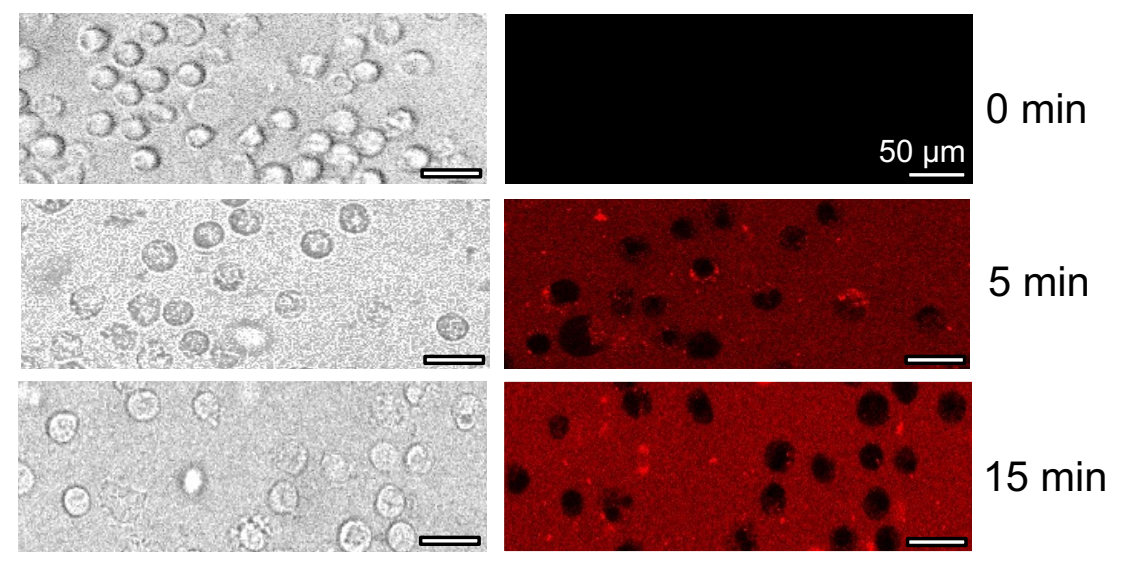

c)

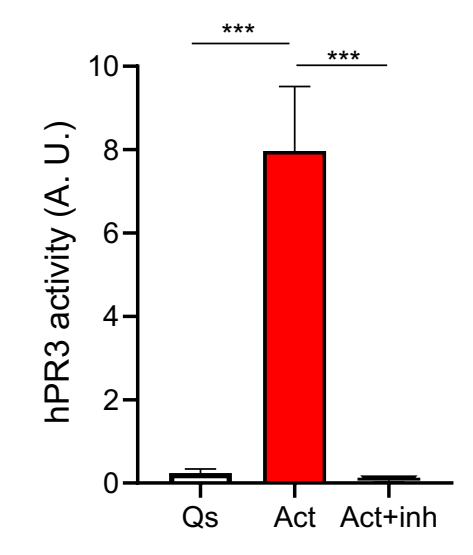

